\title{
Intergroup revenge: a laboratory experiment
}

Authors: David Hugh-Jones* (corresponding author), Martin A. Leroch ${ }^{* *}$

\author{
Affiliations: \\ * University of East Anglia, Norwich Research Park, Norwich NR4 7TJ, United Kingdom. \\ Email: d.hugh-jones@uea.ac.uk \\ ** University of Mainz, Institute of Political Science, 55099 Mainz, Germany. Email: \\ leroch@politik.uni-mainz.de
}




\title{
Intergroup revenge: a laboratory experiment
}

\begin{abstract}
Several everyday examples imply that humans reciprocate not only towards direct perpetrators, but also to entire groups, thereby potentially affecting innocent bystanders. We test the hypothesis that people are predisposed to reciprocate against groups. In a laboratory experiment, subjects who were helped or harmed by another player's action reacted by helping or harming another member of that player's group. This group reciprocity was only observed when one group was seen as unfairly advantaged. Thus, activation of group reciprocity may be a causal mechanism that links perceived injustice to intergroup conflict. We discuss the relevance of group reciprocity to political and economic phenomena including violence, discrimination and team competition.
\end{abstract}

Key Words: Experiment, Intergroup revenge, Fairness, Group identity JEL: D03, D74 


\section{Introduction}

Humans categorize themselves and others by group membership. While such categorization need not necessarily affect behavior, at times it certainly does. In this paper, we analyze how group membership affects behavior of recipients of actions towards innocent third parties, who happen to share the group membership with a previous, initial actor. More specifically, we want to know if, and if so under which circumstances, revenge is not only oriented at direct perpetrators, but expands to the entire group they belong to.

At first sight it appears straightforward that people take revenge against entire groups, not only against direct individual perpetrators, even in routine social and economic life. For instance, consumers buy fewer products from countries which they see as politically antagonistic (Klein et al. 1999, Leong et al. 2008). Further, on days after terrorist bombings in Israel, Jewish (Arab) judges become more likely to favor Jewish (Arab) plaintiffs in their decisions, and Israeli Arabs face higher prices for used cars (Shayo and Zussman 2011, Zussman 2012). On a political level, for instance, Keynes (1922) perceived the Treaty of Paris' devastation of the German economy as an act of revenge, and quoted Thomas Hardy's play The Dynasts: "Nought remains / But vindictiveness here amid the strong, / And there amid the weak an impotent rage." In its most extreme case, revenge against groups may trigger violent intergroup conflict. After an argument between an Indian Dalit and an upper caste farmer, upper caste villagers attacked 80 Dalit families (Hoff et al. 2011). In Atlanta, 1906, after newspaper allegations of black attacks on white women, a group of white people rioted, killing 25 black men (Bauerlein 2001). In both cases, innocent people were made to suffer for the real or supposed crimes of others. Many field studies of intergroup violence report similar tit-for-tat processes, with harm to members of one group being avenged by attacks on previously uninvolved coethnics of the original attackers (Horowitz 1985, 2001; Chagnon 1988). 
The psychology of reciprocity may indeed play a part in these phenomena. Laboratory experiments show that humans reciprocate harm done to them, even at a cost to themselves (Fehr and Gächter 2000; Falk and Fischbacher 2006). A natural extension, which would account for the episodes described above, is that humans reciprocate not only towards individuals, but also towards entire groups. We label retaliation against a perpetrator's group members group reciprocity.

However, these examples do not provide conclusive evidence for the motivations underlying group reciprocal behavior. In field studies it is hard to distinguish group reciprocity from ingroup bias under external threat (Sherif et al. 1961), or from strategic considerations, e.g. if people are rewarded for defending their coethnics (Chagnon 1988). Therefore, to identify group reciprocity cleanly, we ran a computerized laboratory experiment.

We emphasize that we do not believe real-world scenarios like those above can be recreated in the lab. This holds especially for episodes of violent conflict. However, experimenters can study analogous situations, such as intergroup contests and vendettas (Bornstein et al. 1992, 2003; Weisel and Zultan 2013; Abbink and Herrmann 2009). Here, we test for an individual psychological mechanism which may underlie real-world phenomena. We also examine how inequality and unfairness affect group reciprocity.

Our theory relates to existing work on in-group favouritism. As previous experiments show, people value group membership, and prefer to interact with others from their own group (Hargreaves-Heap and Zizzo 2009; Currarini and Mengel 2012). They cooperate more with ingroup members (de Cremer and van Vugt 1999; Goette et al. 2006; Guala et al. 2012). Group members give more to each other, punish each other less and reward each other more (Bernhard et al. 2006; Chen and Li 2009; Currarini and Mengel 2012). Shared group identity may also provide a simple coordination mechanism for individuals (Chen and Chen 2011). However, these phenomena appear insufficient to explain extreme prejudice of the form outlined above or even violence against outgroups (Brewer 1999). Indeed, in-group bias 
disappears when subjects allocate a "bad" such as exposure to aversive noise (Mummendey et al. 1992). In response to this explanatory gap, psychologists have developed theories of intergroup emotions, including "vicarious retribution", a propensity to retaliate against groups (Lickel et al. 2006). We extend this literature by conducting an incentivized experiment which identifies group reciprocity, while avoiding a number of confounds. Of existing experiments, some have examined only verbal attitudes (Stenstrom et al. 2008), while others cannot cleanly distinguish individual-level reciprocity from group reciprocity, because the reciprocator's choices affect the whole outgroup including the individual who committed the offence (Gaertner et al. 2008, Abbink and Herrmann 2009). Our design makes it clear to subjects that they are interacting with different members of the same group.

Our experiment also differentiates group reciprocity from "generalized" or "downstream indirect" reciprocity. This is a phenomenon in which another person's helpful/harmful behaviour causes the subject to help/harm other people in general (Dufwenberg et al. 2001, Greiner and Levatti 2005, Stanca 2009). Generalized reciprocity could be supported by various mechanisms, including learning, imitation, or changes in mood. By contrast, group reciprocity is directed specifically against the original offender's group, not just against people in general. We distinguish group reciprocity from generalized reciprocity by including control treatments where subjects can reciprocate against a "neutral" third party.

As well as testing for the existence of group reciprocity, we also make a start at understanding its correlates. We examine the relationship between group reciprocity and fairness perceptions. Qualitative studies and cross-country regressions both show a link between inequality, unfairness, and intergroup conflict (Tambiah 1996; Horowitz 2001; Cederman et al. 2011). In different experimental sessions we varied the perceived unfairness of intergroup allocations, by allocating a reward to one group either randomly, or as the reward for group performance in a quiz. We show that group reciprocity is only observed when rewards are allocated randomly - a treatment which subjects perceived as less fair. Also, subjects who perceived the experiment as 
less fair were more likely to group-reciprocate.

\section{Experimental Design}

Our experiment consisted of three stages: a group-induction stage, a stage with the economic games, and a post-experimental questionnaire. We first describe the stages on a more general level before detailing the games subjects played.

\subsection{Experimental Stages}

In the first stage, we induced group identity. Subjects were randomly allocated into four colorcoded groups of four: green, orange, purple, and brown. Each subject's color group was shown throughout the experiment by a colored strip at the side of the screen. Subjects then played a quiz, consisting of 20 trivia questions, with their group members, during which they could communicate by chat. ${ }^{1}$ After the quiz, subjects were rewarded for group performance. Each group member's correct answer was rewarded with 10 Experimental Currency Units (ECU, 1 $E C U=5$ Euro cent) for the group. A group's earnings were divided equally among its members. $^{2}$

In addition, in 12 of our 15 sessions, members of one randomly selected group received a 100 ECU bonus. In the remaining three sessions, the group with the highest score in the quiz received the bonus. We used these random bonus and winner bonus sessions to manipulate perceptions of intergroup fairness. ${ }^{3}$ The group receiving the bonus was announced directly after

\footnotetext{
${ }^{1}$ It was forbidden to communicate personal information. All subjects followed these instructions.

${ }^{2} 100$ ECU per subject were described as an endowment for the second part of the experiment. To ensure that each subject had at least $100 \mathrm{ECU}$, minimum group earnings of $400 \mathrm{ECU}$ were implemented. This endowment was purely a framing manipulation to increase subjects' sense that they had "earned" their ECU.

${ }^{3}$ The reason for the imbalance between the number of sessions in each treatment is as follows: we wished to examine individual-level correlates of group reciprocity, so we ran extra sessions using the random bonus treatment which turned out to induce group reciprocity. Note that our results are significant when aggregating across all types of sessions.
} 
the quiz. Subjects then answered a brief questionnaire, including the question "How fair did you think the quiz was?" with answers on a Likert scale from 1 to 5 . We expected that subjects would perceive a bonus to the winning team as fairer than a randomly given bonus (cf. Ball and Eckel 1998, Cherry et al. 2002).

The second stage was the core of our experiment. In it, subjects played eight repetitions of two rounds of a two-player linear public goods game (PGG). In each public goods game, both subjects shared a fund of 100 ECU. Each subject could take up to 50 ECU out of the fund. ECU remaining in the fund were multiplied by 1.5 and shared equally between the two.

The basic structure of each repetition was as follows: subjects played a PGG with one other subject, from a set of four subjects. They then received feedback about exactly one other subject's play from the four. Lastly, they played another PGG with one other subject from the four. This two-round structure allows subjects to observe another player's behaviour in the first round, and react to it in the second round. The details of the matching protocol are described in detail below. After the second round, subjects learned the choices of both their partners, and their total earnings from the repetition. Total earnings from one randomly chosen repetition were used for payment.

We framed the game as a decision to "take" ECU from the common fund in order to emphasize that this decision would harm the other player. ${ }^{4}$ In the public goods game, actions that harm the other are beneficial to oneself. This makes our results comparable to previous work which uses public goods games to measure individual-level reciprocity (e.g. Fischbacher et al. 2001). It would also be interesting and important to use a game in which other-harming actions were costly.

\subsection{Matching}

\footnotetext{
${ }^{4}$ By "harm", we simply mean "reduce the other's earnings". We cannot be sure whether our subjects perceived taking from the common fund as harmful or simply as not helpful, since this depends on what they perceived to be the default or baseline action.
} 
Within each of the eight repetitions, subjects were matched in groups of four. Matching was different in different treatments (which varied across repetitions, i.e. this is a within-subject design). These treatments were designed to identify group reciprocity, while avoiding several potential confounds.

Group reciprocity occurs when (a) a second party helps/harms the subject and (b) the subject responds by helping/harming another person in the second party's group. To distinguish group reciprocity from individual reciprocity, the subject must know that the original person in part (a) is different from the person she helps/harms in part (b). We did this as follows: in each of the eight repetitions, subjects were shown the sets of four in which they were interacting. All four subjects' color groups were represented on screen by colored circles, along with the subjects' earnings from the quiz. We used arrows on screen to show each subject his or her partners for the first round PGG, and for the second round PGG.

In first party/same group repetitions, subjects received feedback on their own partner's play in the first PGG. This partner is labelled P1 in Figure 1. In the second round, subjects played against a different player (labelled P2). P2 was in the same group as P1. Thus, subjects learnt about how P1 had played against them in the first round, and could then react to this by playing differently against P1's group member, $\mathrm{P} 2$.

Subjects might react to P1's play by playing differently against all players, not just against P1's group members. This would be generalized reciprocity, as described above. To control for this, in first party/different group treatments, $\mathrm{P} 2$ was a member of a third, neutral group - neither the subject's own group, nor P1's group. ${ }^{5}$

Thus, if we see a correlation between P1's choice in the first round PGG with the subject, and the subject's choice in the second round PGG against P2, this could be due to generalized reciprocity or group reciprocity. If this correlation is higher in the first party/same group

\footnotetext{
${ }^{5}$ Subjects might become more generous to other members of their own group in the face of an external threat (e.g. Sherif et al. 1961). To avoid this potential confound, we ensured that P2 was never from the subject's own group.
} 
treatment, where P1 and P2 share a group membership, this can be ascribed to group reciprocity alone.

Figure 1 summarizes the first party/same group and first party/different group treatments. 


\section{First party/same group}
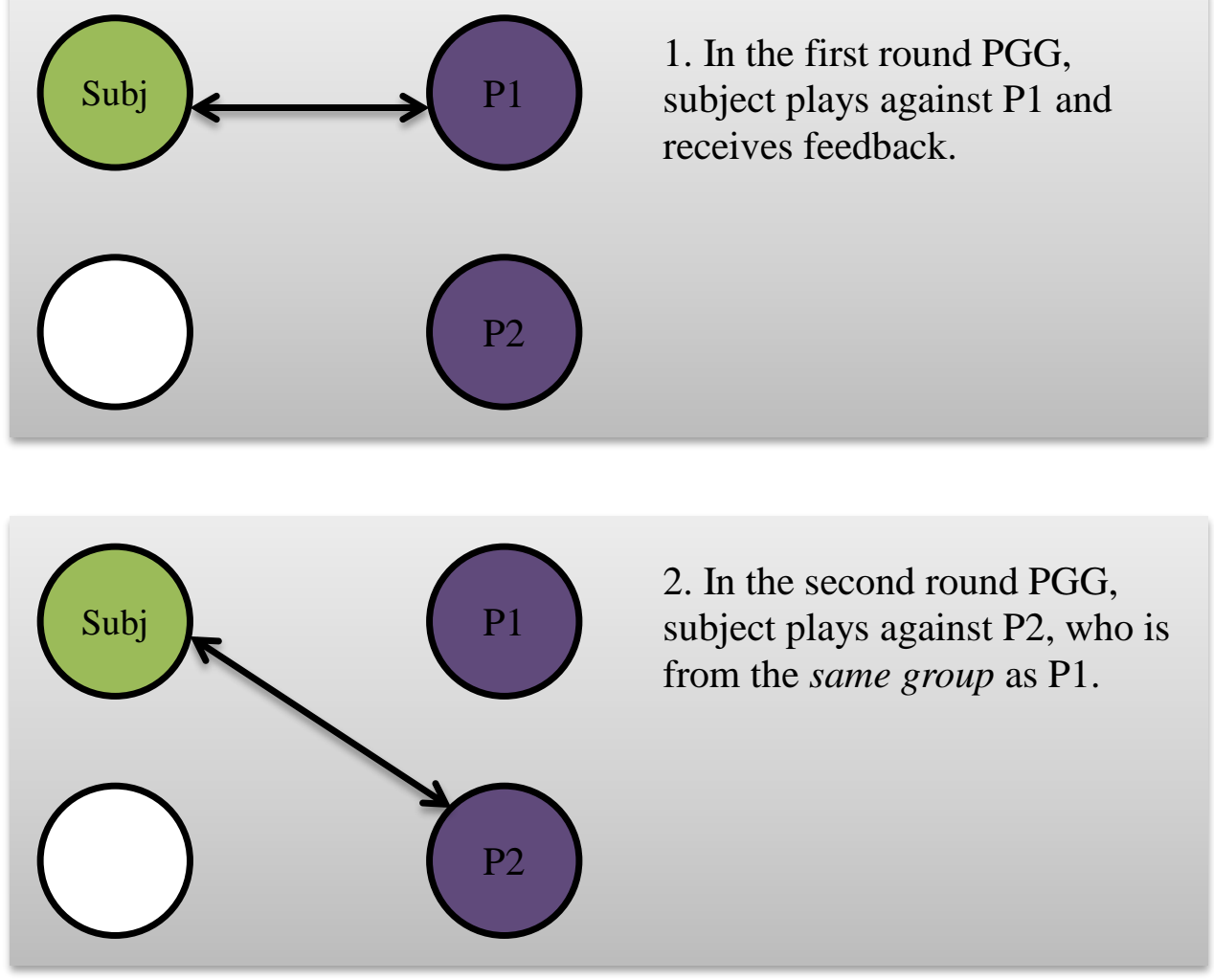

\section{First party/different group}
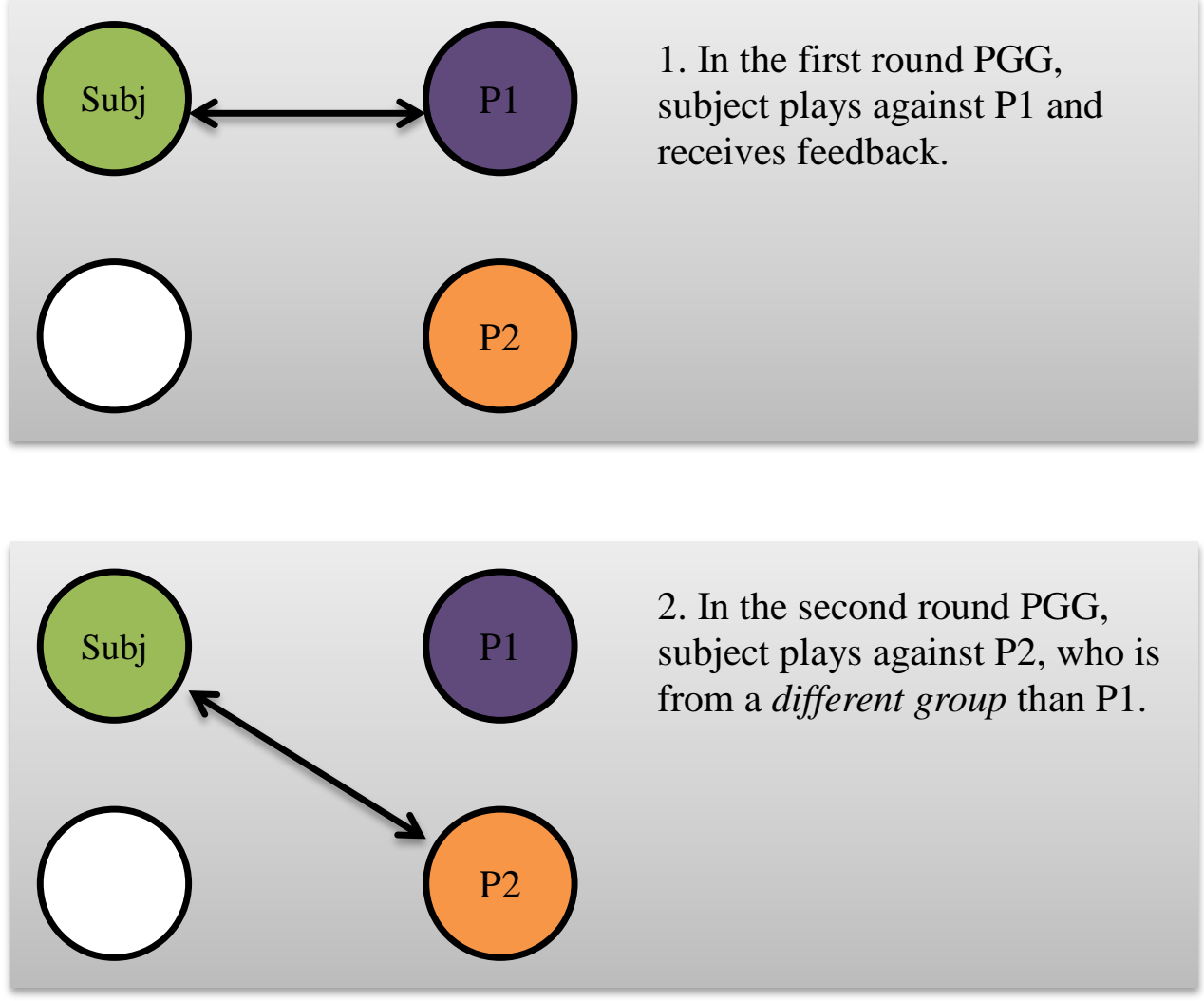

Figure 1: first party treatments 
The first party treatments examine how subjects respond to an outgroup member helping or harming them. Subjects might also respond to an outgroup member helping or harming someone else (say, someone else in the subject's group), by helping or harming others in that outgroup. For example, ethnic riots often start when people take revenge on perceived slights offered to their co-ethnics or co-religionists (Horowitz 2001).

The third party/same group and third party/different group treatments were designed to examine this. In these treatments, after the first round, subjects did not learn how their own partner played. Instead they learned how another player had played against someone else. They then played the second PGG against their first round partner again (whom we label P2, i.e. in all treatments, P1 is the first round player about whom the subject receives feedback, and P2 is the subject's partner in the second round). As before, in same group treatments, P2 was in P1's group, while in different group treatments, P2 was in an uninvolved neutral group. As before, subjects might react to P1's play in the first PGG, by playing differently in the second PGG. If subjects reciprocate specifically against P1's group members, we will see more reciprocity in the same group treatment than in the different group treatment. ${ }^{6}$ Figure 2 summarizes the third party/same group and third party/different group treatments.

Between repetitions, subjects were rematched into different sets of 4 . The rematching was fixed so that all subjects experienced all treatments over the 8 repetitions. ${ }^{7}$ This within-subjects design allows more accurate inferences about group reciprocity's individual-level covariates. Treatments were balanced across repetitions and colour groups.

After the eight repetitions, subjects answered a survey and were paid privately.

\footnotetext{
${ }^{6}$ In third party repetitions, we also varied whether the feedback player P1 was playing against someone from the subject's own group, or someone from a different, neutral group. This allows us to examine whether subjects react more strongly when P1's action affects a member of the subject's own group. As overall results from third party treatments were null, we do not report further on this here.

${ }^{7}$ Two of our sessions used only the first party treatment.
} 


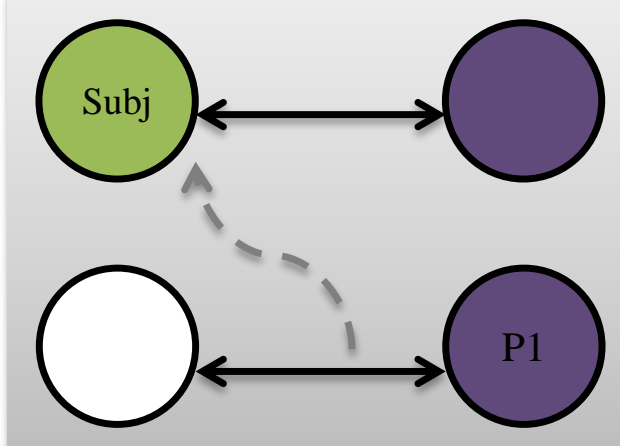

1. In the first round PGG, subject plays against the horizontal player. S/he receives no feedback about this game, but receives feedback about P1's play against the other member of the foursome.

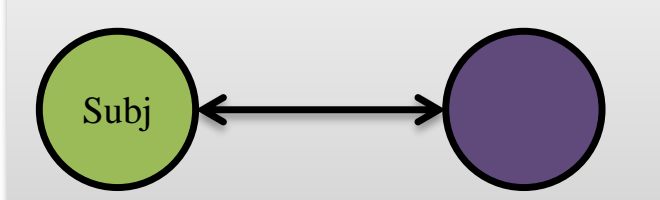

2. In the second round PGG, subject plays against the horizontal player again. This player is from the same group as $\mathrm{P} 1$.
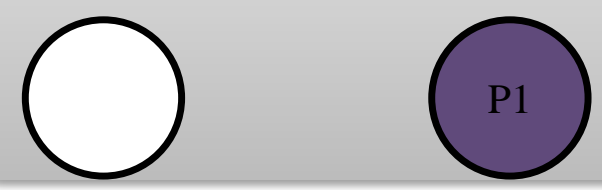

\section{$\underline{\text { Third party/different group }}$}
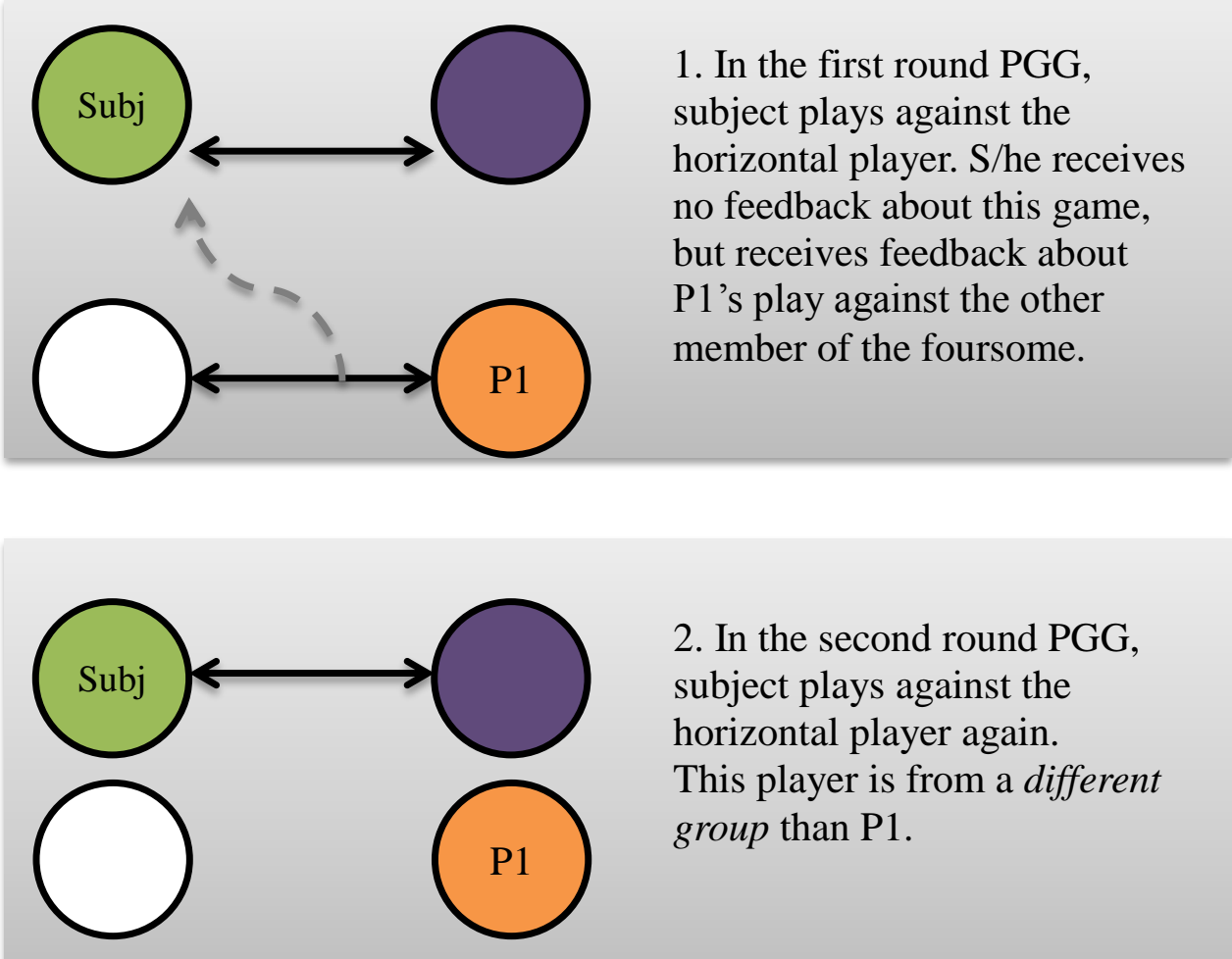

2. In the second round PGG, subject plays against the horizontal player again. This player is from a different group than P1. 


\subsection{Variations}

Some repetitions and sessions varied this basic setup.

One driver for group reciprocity might be changes in beliefs. For example, seeing someone from another group play selfishly, the subject might expect others from that group to do the same, and adjust her own play accordingly. To test how far this explains group reciprocity, in two of the eight repetitions, we elicited subjects' beliefs about their second round partner's play. Guesses were monetarily incentivized.

We also looked at this in another way. In sessions 11 and 12, we did not elicit beliefs. Instead, in each set of four, one subject's second round partner had an action chosen randomly for them by the computer, rather than being able to choose themselves. This was announced to both players before they made their choices. If expectations of the second round partner's play drives group reciprocity, we would expect group reciprocity to disappear when the second round partner's choice is made random. To gather more relevant data, these sessions only include first party treatments.

In three sessions, we included a second quiz after half of the public goods games were played. Subjects played the quiz in a team consisting of members of other groups. This was to test the idea that cooperation with outgroup members in a joint task can reduce intergroup prejudice (Gaertner et al. 1993). Since results were null, we do not analyse this further here.

In total, we ran 15 sessions of 16 subjects each. Table 1 below summarizes the different variations in each session. 
Table 1: summary of sessions

\begin{tabular}{lllll} 
Sessions & Treatments & Quiz bonus & Beliefs? & Second quiz? \\
\hline $\mathbf{1 - 3}$ & First and third party & Winning team & Elicited & No \\
$\mathbf{4 - 1 0}$ & First and third party & Random team & Elicited & No \\
$\mathbf{1 1 - 1 2}$ & First party only & Random team & Random decisions & No \\
$\mathbf{1 3 - 1 5}$ & First and third party & Random team & Elicited & Yes \\
\hline
\end{tabular}

The experiment took place in the computer laboratory of the University of Hamburg, using the software zTree (Fischbacher 2007). Subjects were recruited from the laboratory's pool via ORSEE (Greiner 2004). 240 subjects participated on four separate days. ${ }^{8}$ Sessions lasted about an hour. Average earnings per session were 14.48 EUR.

\section{Model}

Here is a simple formal framework to help interpret our results. Suppose a subject interacts in sequence with two other agents. His or her utility is given by

$$
u\left(p, k_{1}, k_{2}\right)=V(p)+\left(\mu+v \boldsymbol{1}_{\text {SameGroup }}\right) k_{2}+\left(\beta+\delta \boldsymbol{1}_{\text {SameGroup }}\right) k_{1} k_{2}
$$

where $p$ is own material payoff, $V(\cdot)$ is a weakly concave function of $p, k_{l}$ is the first agent's kindness to the subject and $k_{2}$ is the subject's kindness to the second agent. The indicator variable $\boldsymbol{1}_{\text {SameGroup }}$ takes the value 1 when the two other agents share group membership, and 0 otherwise. Subject's kindness to agent $j$ can be measured as $\left(p_{j}-p_{\min }\right) /\left(p_{\max }-p_{\min }\right)$ where $p_{j}$ is $j$ 's actual material payoff, and $p_{\max }$ and $p_{\min }$ are his maximum and minimum material payoffs over the set of the subject's possible actions, taking $j$ 's own action as given.

The second term in this equation, $\mu+v \boldsymbol{1}_{\text {SameGroup }}$, represents altruism, where $\mu$ represents unconditional altruism towards others, irrespective of their group membership, and $v$ allows for different levels of altruism towards members of specific groups. The third term, $\beta+\delta \boldsymbol{1}_{\text {SameGroup }}$, represents reciprocity, and parametrizes the increase in utility when agent 1 is kinder/unkinder

\footnotetext{
${ }^{8}$ The online appendix shows participants' descriptive statistics, including demographics.
} 
to the subject and the subject is kinder/unkinder to agent 2. This specification is similar to Rabin (1993). More complex representations of kindness and reciprocity are plausible. For example, kindness might depend on a comparison between the actions of the other agent and of the subject. However, the approach above has the advantage of simplicity and clarity. $\beta$ represents the baseline level of generalized reciprocity for two other agents who are not in the same group. Our parameter of interest is $\delta$. This measures the increase in reciprocity when agents 1 and 2 are in the same group: that is, the level of group reciprocity. We expect that $\delta>$ 0. Group reciprocity on behalf of a third party can be analysed in this framework by letting $k_{1}$ be the first agent's kindness to another player, as observed by the subject.

\section{Results}

Our estimation is based on equation (1). Let $P 1$ take be the amount taken out of the common fund by participant P1 in the first PGG, whose choice is observed by the subject. Second round take is the amount taken by the subject out of the common fund in the second PGG, when playing against $\mathrm{P} 2$. Then $k_{1}=\left(1-P 1\right.$ take/50) and $k_{2}=(1-$ Second round take/50). Using a quadratic for material welfare $V(p)$, and taking the first order condition, gives:

$$
\text { Second round take }=\alpha+\beta \text { P1 take }+\gamma \text { Same group }+\delta \text { Same group } \times \text { Pl take }
$$

where $\beta$ and $\delta$ are the reciprocity coefficients defined in (1) above. ${ }^{9}$

Our first result is:

Result 1: There is significant evidence of first party group reciprocity across all sessions, and within random bonus sessions, but not within winner bonus sessions.

To give a sense of Result 1, Figure 3 plots $P 1$ take against Second round take in first party

\footnotetext{
${ }^{9}$ A derivation is in the online appendix.
} 
treatments during random bonus sessions. The slope of the lines gives the correlation between P1's behaviour in the first PGG, and the subject's behaviour when playing P2 in the second PGG. This slope was roughly doubled when P1 and P2 were from the same group. Differences are largest when P1 took either 0 or 50 from the common fund: between them, these categories account for slightly more than $50 \%$ of observations. 


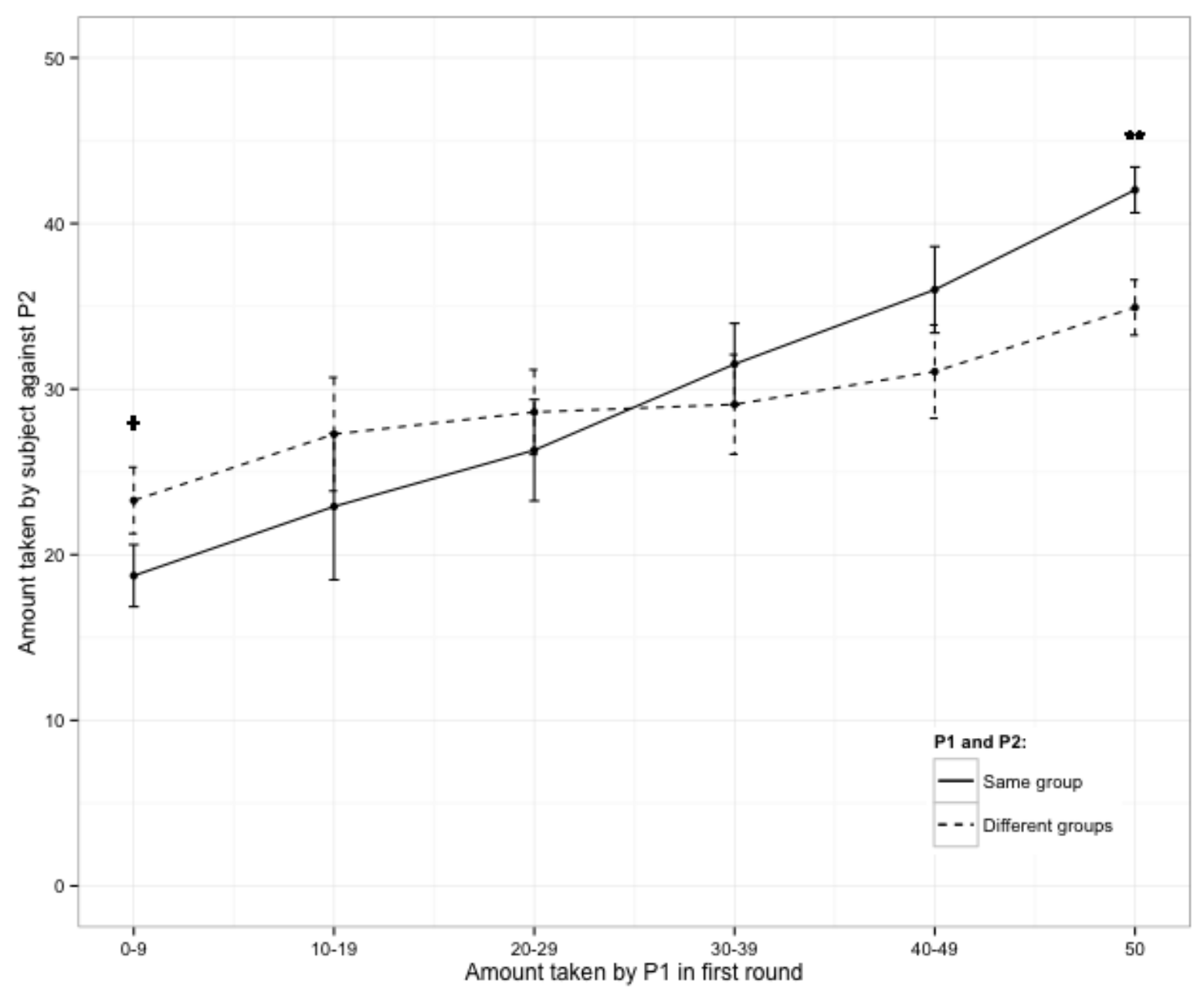

Figure 3: The $\mathrm{X}$ axis shows the amount taken from the common fund in the first round PGG, by the subject's partner P1. The Y axis shows the average amount taken from the common fund in the second round PGG by the subject, against $\mathrm{P} 2$. The dashed line shows first party/different group treatments. The solid line shows first party/same group treatments. Only random bonus sessions are plotted. Bars show \pm 1 s.d. $+\mathrm{p}<0.10 ; * * \mathrm{p}<$ 0.01 . 
Subjects' choices within a session may not be independent. As a conservative test of significance, we estimate $\beta$ and $\beta+\delta$ in equation (2) separately for each session, and treat them as a single matched pair of observations. Within first party treatments, $\beta+\delta$ was higher than $\beta$ in 11 out of 12 random bonus sessions, but in no winner bonus sessions. A signed-rank test on the matched pairs rejects the null that $\delta=0$ over all sessions at $p=0.0353$ (two-sided), and over random bonus sessions only at $p=0.00928$ (two-sided).

We confirm Result 1 in an individual-level regression. Table 2 estimates equation (2) for first party treatments. Column 1 pools data from all sessions, columns 2 and 3 use random and winner bonus sessions respectively. Regressions include dummy variables for periods and for subjects (i.e. fixed effects). Standard errors are clustered at individual level. The coefficient on Pl take is not significantly different from zero: in other words, there is no evidence for generalized reciprocity. By contrast, the $\delta$ coefficient on Pl take $\times$ Same group is always positive. It is significant in random bonus sessions and across all sessions, but not in winner bonus sessions. These results are robust to alternative specifications. ${ }^{10}$

\footnotetext{
${ }^{10}$ These include removing the fixed effects; using session- rather than individual-clustered standard errors; adding controls for the history of play; and running Tobit regressions.
} 
Table 2: Estimates of group reciprocity, first party treatments. The dependent variable is the amount taken by subjects against P2 in round 2 of the PGG. $+p<0.10 ; * p<0.05 ; p<0.01$; $* * * \mathrm{p}<0.001$. Standard errors clustered by subject.

\begin{tabular}{llll}
\hline & $(1)$ & $(2)$ & $(3)$ \\
\hline P1 take $(\beta)$ & 0.0289 & 0.0287 & -0.0107 \\
& $(0.0348)$ & $(0.0386)$ & $(0.0801)$ \\
Same group $(\gamma)$ & -4.08 & -3.94 & -5.94 \\
& $(1.59) *$ & $(1.75) *$ & $(4.13)$ \\
P1 take $\times$ Same group $(\delta)$ & 0.179 & 0.185 & 0.202 \\
& $(0.0474) * * *$ & $(0.0525) * * *$ & $(0.112)+$ \\
\hline Model & Linear & Linear & Linear \\
Controls & Indiv. and period dummies & Indiv. and period dummies & Indiv. and period dummies \\
$\mathrm{N}$ & 1024 & 832 & 192 \\
$\mathrm{~N}$ indiv. & 240 & 192 & 48 \\
Adj. R2 & 0.0322 & 0.0353 & 0.0228 \\
\hline
\end{tabular}

Our second result is a null one:

Result 2: Subjects showed no third party group reciprocity in either winner or random bonus sessions.

In third party treatments, $\beta+\delta$ was higher than $\beta$ in 7 out of 10 random bonus sessions and 2 out of 3 winner bonus sessions ( $p=0.216$, two-sided, over all sessions).

Table 3 estimates equation (2) for third party treatments. P1 take $\times$ Same group has a small effect. The effect is weakly significant in winner bonus sessions, but this is not robust to alternative specifications.

Thus, we did not find evidence for third party group reciprocity. One explanation is that third party group reciprocity may require both a perception of outgroup entitativity, and strong identification with one's own group. With a stronger group treatment, group reciprocity and ingroup altruism could combine to create third party group reciprocity. Alternatively, our design may have led subjects to focus on their own first-round public goods game, treating feedback from the other pair's game as less salient. We see this as an important topic for future research, since the scope of real-world conflicts often expands when third parties are drawn into existing 
disputes.

Table 3: Estimates of group reciprocity, third party treatments. The dependent variable is the amount taken by subjects against P2 in round 2 of the PGG. $+p<0.10 ; * p<0.05 ; p<0.01$; $* * * \mathrm{p}<0.001$. Standard errors clustered by subject.

\begin{tabular}{llll}
\hline & $(1)$ & $(2)$ & $(3)$ \\
\hline P1 take $(\beta)$ & 0.0641 & 0.0711 & -0.00448 \\
& $(0.0407)$ & $(0.0477)$ & $(0.0759)$ \\
Same group $(\gamma)$ & -0.914 & 0.257 & -8.25 \\
& $(1.82)$ & $(2.12)$ & $(3.77) *$ \\
P1 take $\times$ Same group $(\delta)$ & 0.0666 & 0.0366 & 0.205 \\
& $(0.0536)$ & $(0.0629)$ & $(0.108)+$ \\
\hline Model & Linear & Linear & Linear \\
Controls & Indiv. and period dummies & Indiv. and period dummies & Indiv. and period dummies \\
$\mathrm{N}$ & 832 & 640 & 192 \\
$\mathrm{~N}$ indiv. & 208 & 160 & 48 \\
Adj. R2 & 0.0157 & 0.012 & 0.0407 \\
\hline
\end{tabular}


Next, we look at correlates of group reciprocity, focusing on first party treatments in random bonus sessions. First, we test the hypothesis that group reciprocity is linked to perceptions of unfairness. Our post-quiz questionnaire included a 1-5 Likert scale "Did you feel that the quiz was fair?" Figure 4 shows the distribution of answers, by session type. Answers were less positive in random bonus sessions (Goodman and Kruskal's gamma, $p=0.072$ ). This difference may explain why we observe group reciprocity in random bonus sessions only. We can also test the hypothesis more directly.

Result 3: Subjects who perceived the quiz as unfair displayed more group reciprocity.

Column 1 of Table 4 interacts equation (2) with a dummy variable Fair, which is 1 if the subject perceived the quiz as fair or very fair. The coefficient on P1 take $\times$ Same group $\times$ Fair is negative and significant at the $10 \%$ level, and the summed coefficient is not significantly different from zero. Subjects who perceived the quiz as unfair were about two-and-a-half times more group-reciprocal $(0.271$ versus $0.271-0.174=0.097) .{ }^{11}$

Our next result concerns expectations. Observing P1's actions might change the subject's expectations about other members of P1's group, including the subject's second round partner P2. Subjects might then behave differently to P2 because of these expectations, rather than because they directly wished to harm other members of P1's group. This would be a kind of statistical discrimination (Arrow 1972). ${ }^{12}$ Alternatively, group reciprocity may be "taste based": subjects simply want to harm co-group-members of someone who has harmed them.

\footnotetext{
${ }^{11}$ This is within random bonus sessions only. Results are similar in winner bonus sessions. Controlling for fairness perceptions reduces, but does not eliminate, the difference between sessions.

${ }^{12}$ In fact, there were no significant correlations within groups.
} 


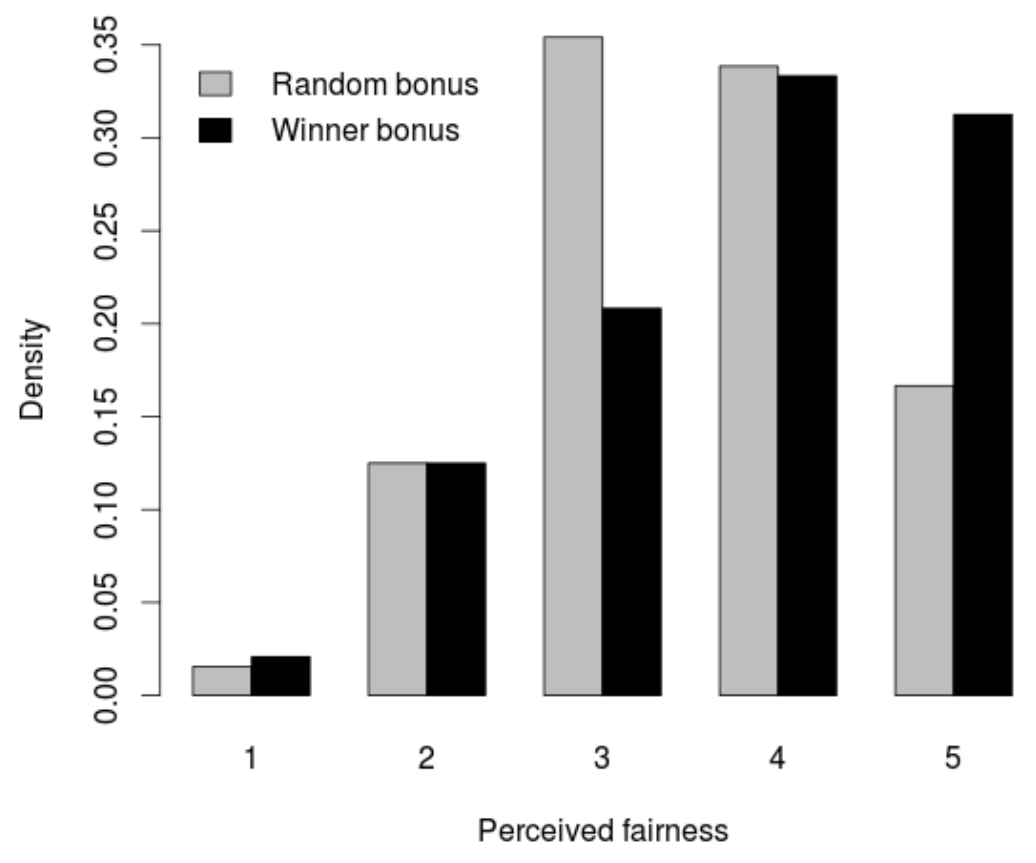

Figure 4: Histogram of perceived fairness in random and winner bonus sessions ( 1 = "very unfair", 5 = "very fair") 
Result 4: Group reciprocity remained significant after controlling for subjects' expectations of their second round partners' choices.

In repetitions 2 and 7 of sessions 1-10 and 13-15, we elicited subjects' Expectations about their second round partner's choice. These were incentivized by a payment based on the difference between the guess and the true amount taken by the partner. Column 2 of Table 4 adds Expectations to the basic regression. To increase efficiency, we multiply impute Expectations for repetitions where it was not elicited. ${ }^{13}$ Since the missingness of Expectations is wholly determined by the repetition number, it is "missing at random" with respect to Expectations once repetitions are controlled for, so that multiple imputation will be unbiased. Multiple imputation was done with the Amelia II software. ${ }^{14}$ Expectations is highly significant, and the coefficient on Pl take $\times$ Same group shrinks by about a third. However, it remains significant.

We also used another way to control for the effect of expectations. In each repetition of sessions 11 and 12, one player's second round take was determined randomly, by a computerized draw from the uniform distribution on $\{0, \ldots, 50\} .{ }^{15}$ Their second round partners knew this, and both partners were paid as normal. Subjects' expectations about P2's play ought not to be affected by P1's play when P2's play is randomly determined. Column 3 of Table 4 interacts equation (2) with a dummy variable $P 2$ random. The coefficient on $P 1$ take $\times$ Same group $\times P 2$ random is actually positive, although the summed coefficient is imprecisely estimated.

Overall, both expectations and preferences seem to matter for group reciprocity. However, we

${ }^{13}$ If we do not multiply impute Expectations, we lose all repetitions other than 2 and 7. Results on repetitions 2 and 7 alone are insignificant whether or not Expectations are included.

${ }^{14}$ Expectations was imputed from the following variables: first round amount taken by participant F, first and second round amounts taken by the subject and his/her own round 1 and round 2 partners, lags of these amounts from the previous repetition; amount the subject last saw taken by a participant from the same colour group as the current partner; a quadratic in repetition (from 1 to 8 ), and treatment dummies.

${ }^{15}$ To gather more information, these sessions only included first party treatments, with two repetitions of each color treatment. 
caution that in our setup, controlling for expectations is intrinsically hard. Ideally, this could be done in a one-shot experiment.

We argue that group reciprocity can be motivated by fairness concerns. To test this another way, we examine whether, in random bonus sessions, more group reciprocity is displayed towards members of the team that won the random bonus. Column 4 of table 4 interacts equation (2) with a dummy for if the round 2 partner is a Bonus winner. The interaction term $P 1$ take $\times$ Same group $\times$ Bonus winner is positive, but not significant. However, our results vary with the regression specification, and we are not confident that we can definitively answer this question, so we do not report a result.

Lastly we examine how identity concerns relate to intergroup reciprocity. Social Identity Theory (SIT) holds that individuals support their group, and discriminate against other groups, in order to protect the self-esteem they derive from their social identity as a group member. If revenge is a form of group discrimination, SIT would predict that subjects with the strongest ingroup identity will be most likely to take group revenge. Our final questionnaire included standard measures of group identity. Subjects indicated their level of agreement on a 7-point Likert scale to two statements: "I felt commited to my group" and "Members of the green/orange/purple/brown group worked well together as a team". We sum answers to these to create the variable Group ID. We found:

Result 5: Subjects with higher levels of in-group identification showed higher levels of group reciprocity.

Column 5 of Table 4 interacts equation (2) with Group ID. The interaction term P1 take $\times$ 
Same group $\times$ Group ID is significant at the $5 \%$ level. ${ }^{16}$

${ }^{16}$ A pooled linear regression without fixed effects also gives a significant result at 5\%. A Tobit model and a linear regression model including controls for the history of play did not reach significance, although the coefficients had the same signs. 
Table 4: Estimates of group reciprocity, first party treatments, random bonus sessions.

Dependent variable: amount taken by subjects in the round 2 PGG. Robust standard errors clustered by individual in parentheses. $+\mathrm{p}<0.10 ; * \mathrm{p}<0.05 ; \mathrm{p}<0.01 ; * * * \mathrm{p}<0.001$.

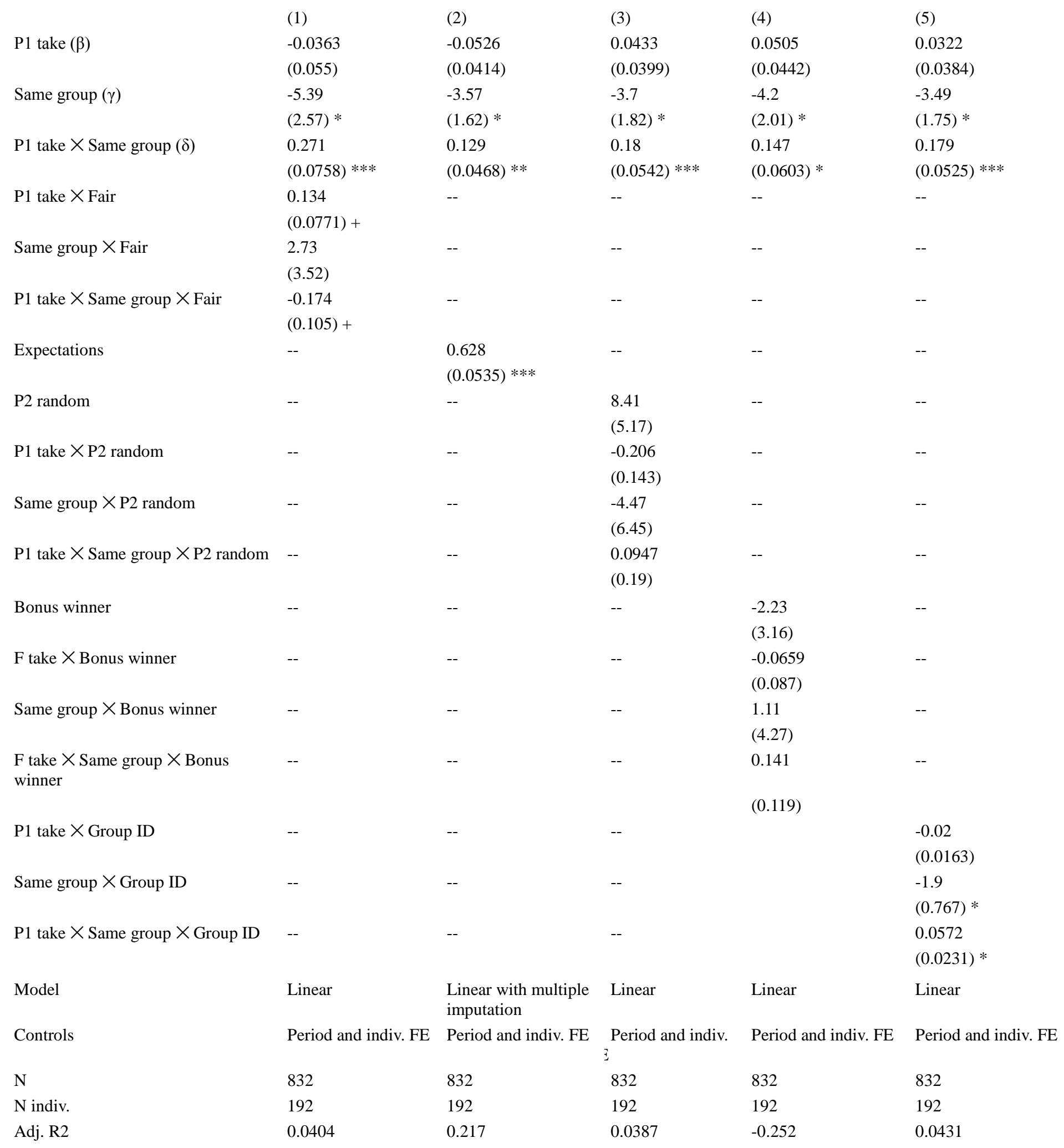




\section{Conclusion}

Our experiment reproduced intergroup revenge in a controlled laboratory setting. When subjects were harmed in a public goods game, they reciprocated the same way against other people in their partner's group, but not against members of a control group.

Although subjects' behaviour appears to be reciprocal, other explanations are also possible, such as a desire to equalize payoffs with members of a specific outgroup. This is analogous to possible interpretations of ultimatum game behaviour (Güth et al. 1982; Falk et al. 2003). More research is needed to understand the motivations behind the choices observed here.

Much existing experimental work examines short or one-shot games (Fershtman and Gneezy 2001; Chen and Li 2009; Habyarimana et al. 2009; cf. Bornhorst et al. 2010). Subjects begin an interaction with a predetermined or experimentally induced level of in-group bias, which affects their choices. Our paper complements this approach by examining intergroup dynamics. For instance, many conflicts are driven by cycles of revenge, in which bystanders are harmed for their fellow group members' actions. Some observers blame not deep intergroup hatreds but self-interested politicians and hired thugs (Brass 1997; Kaufman 2001; cf. Glaeser 2005). Our results show that even absent these factors, humans may take revenge upon groups. But subjects only did so when there were arbitrary between-group inequalities, which were associated with lower perceptions of fairness.

We suggest three areas for future research. Firstly, experiment participants did not reciprocate for actions affecting other people, even other in-group members. Reciprocation by third parties may be important, because it causes conflict to spread. Stronger group identity treatments, or longer interactions, might lead to third party reciprocity.

Second, our experiment cannot tell us whether group reciprocity is innate or learned. Primates 
appear to reciprocate against attackers' kin (Aureli at al. 1992), suggesting the former. But humans may also learn group reciprocity in response to strategic incentives (Chagnon 1988; Hardin 1995; Fearon and Laitin 1996).

Lastly, we know little about the connection between perceived unfairness and group behavior. We need to understand what contexts create intergroup resentment and how this psychology plays out in particular environments. In public economics, perceptions that certain groups act corruptly or manipulate the tax system may lead disadvantaged groups to behave noncooperatively, e.g. by evading taxes (cf. Alm and Torgler 2006); similarly, the introduction of "unfair" policies may damage intergroup cooperation. Ultimately, understanding intergroup dynamics could help policy-makers to manage them better and to forestall their worst effects.

\section{Acknowledgements}

This work was supported by British Academy Small Research Grant SG101553. We thank Astrid Buba, Vittoria Levati, Werner Güth, Eva Steiger, Johannes Weisser, Ro'i Zultan, David Reinstein, Ryan McKay, Eva van den Broek, Shaun Hargreaves Heap, Brian Lickel, Arthur Lupia, Tore Ellingsen, Lorenz Goette, Alicia Melis, Michelle Brock, Catherine Scacco, Rafael Hortalla-Vallve, Nadine Chlass, Matthew Braham and seminar participants at the Max Planck Institute of Economics, University of Hamburg, University of Warwick, King's College London, University of East Anglia, NYU-CESS, IMEBE, ESA and THEEM for helpful comments; and the Max Planck Institute ESI group hiwis and administrative staff: Martin Beck, Nadine Erdmann, Adrian Liebtrau, Christian Williges, Christian Streubel, Claudia Zellmann and especially Christoph Göring. 


\section{References}

Abbink, Klaus, Benedikt Herrmann. 2009. "Pointless Vedettas."

http://papers.ssrn.com/sol3/papers.cfm?abstract_id=1468452

Akerlof, George A., and Rachel E. Kranton. 2000. "Economics and Identity", Quarterly Journal of Economics 115(3): 715-753.

Akerlof, George A., and Rachel E. Kranton. 2005. "Identity and the Economics of Organizations." Journal of Economic Perspectives 19 (1): 9-32.

Akerlof, George A., and Rachel E. Kranton. 2010. Identity Economics: How Our Identities Shape Our Work, Wages, and Well-Being. Princeton University Press.

Alm, James, and Benno Torgler. 2006. "Cultural differences and tax morale in the United States and Europe.” Journal of Economic Psychology 27: 224-246

Arrow, Kenneth J. 1972. "Some mathematical models of race discrimination in the labor market." Racial discrimination in economic life, pp.187-203.

Arrow, Kenneth J. 1998. "What Has Economics to Say About Racial Discrimination?” The Journal of Economic Perspectives 12 (2) (April 1): 91-100.

Aureli, Filippo, Roberto Cozzolino, Carla Cordischi, and Stefano Scucchi. 1992. "Kin-

Oriented Redirection among Japanese Macaques: An Expression of a Revenge System?" Animal Behaviour, 44(2): 283-291.

Baldwin, Kate, John D. Huber. 2010. "Economic Versus Cultural Differences: Forms of Ethnic Diversity and Public Goods Provision," American Political Science Review, 104(4): 644-662.

Bauerlein, Marc. 2001. Negrophobia: A Race Riot in Atlanta, 1906. New York: Encounter Books.

Ball, Sheryl, and Catherine C. Eckel. 1998. “The Economic Value of Status.” Journal of Socio-Economics 27(4): 495-514.

Bernhard, Helen, Urs Fischbacher, and Ernst Fehr. 2006. "Parochial Altruism in Humans." Nature 442(7105): 912-915.

\section{Bornhorst, Fabian, Andrea Ichino, Oliver Kirchkamp, Karl H. Schlag, and Eyal Winter.} 2010. "Similarities and Differences When Building Trust: The Role of Cultures." Experimental Economics 13 (3): 260-283.

Bornstein, Gary. 1992. “The Free-rider Problem in Intergroup Conflicts over Step-level and Continuous Public Goods.” Journal of Personality and Social Psychology 62 (4): 597.

Bornstein, Gary. 2003. “Intergroup Conflict: Individual, Group, and Collective Interests." 
Personality and Social Psychology Review 7 (2): 129-145.

Brass, Paul R. 1997. Theft of an Idol: Text and Context in the Representation of Collective Violence. Princeton, NJ: Princeton University Press.

Brewer, Marilyn B. 1999. The psychology of prejudice: Ingroup love and outgroup hate?. Journal of Social Issues 55 (3): 429-444.

Cederman, Lars-Erik, Nils B. Weidmann, and Kristian S. Gleditsch. 2011. "Horizontal Inequalities and Ethno-Nationalist Civil War: A Global Comparison.” American Political Science Review, 105(3): 478-495.

Chagnon, Napoleon A. 1988. "Life Histories, Blood Revenge, and Warfare in a Tribal Population." Science, 239(4843): 985-992.

Chen, Roy and Yan Chen. 2011. "The Potential of Social Identity for Equilibrium Selection." American Economic Review, 101(6): 2562-2589.

Chen, Yan and Sherry X. Li. 2009. "Group Identity and Social Preferences.” American Economic Review, 99(1): 431-457.

Cherry, Todd L., Peter Frykblom, and Jason F. Shogren. 2002. "Hardnose the Dictator." American Economic Review 92(4): 1218-1221.

Currarini, Sergio and Friederike Mengel. 2012. "Identity, Homophily and In-Group Bias." FEEM Working Paper 37.

de Cremer, David and Mark van Vugt. 1999. "Leadership in Social Dilemmas: The Effects of Group Identification on Collective Actions to Provide Public Goods.” Journal of Personality and Social Psychology, 76(4): 587-599.

Dufwenberg, Martin, Uri Gneezy, Werner Güth, and Eric Van Damme. 2001. "Direct vs indirect reciprocity: an experiment." Homo Oeconomicus 18: 19-30.

Falk, Armin, Ernst Fehr, and Urs Fischbacher. 2003. "On the nature of fair behavior." Economic Inquiry 41(1): 20-26.

Falk, Armin and Urs Fischbacher. 2006. "A Theory of Reciprocity.” Games and Economic Behavior, 54: 293-315.

Fearon, James D. and David D. Laitin. 1996. "Explaining Interethnic Cooperation.” American Political Science Review, 90(4): 715-735.

Fehr, Ernst and Simon Gächter. 2000. "Cooperation and Punishment in Public Goods Experiments.” American Economic Review, 90(4): 980-994.

Fershtman, Chaim and Uri Gneezy. 2001. "Discrimination in a Segmented Society: An Experimental Approach.” Quarterly Journal of Economics, 116(1): 351-377.

Fischbacher, Urs, Simon Gaechter and Ernst Fehr. 2001. "Are people conditionally 
cooperative? Evidence from a public goods experiment.” Economics Letters, 71(3): 397-404.

Fischbacher, Urs. 2007. "z-Tree: Zurich Toolbox for Ready-Made Economic Experiments." Experimental Econics, 10(2): 171-178.

Gaertner, Samuel L., John F. Dovidio, Phyllis A. Anastasio, Betty A. Bachman, and Marcy C. Rust. 1993. "The Common Ingroup Identity Model: Recategorization and the Reduction of Intergroup Bias." European Review of Social Psychology, 4(1): 1-26.

Gaertner, Lowell, Jonathan Iuzzini, and Erin M. O'Mara. 2008. "When Rejection by One Fosters Aggression Against Many: Multiple-Victim Aggression as a Consequence of Social Rejection and Perceived Groupness.” Journal of Experimental Social Psychology 44: 958-970.

Glaeser, Edward. L. 2005. "The Political Economy of Hatred." Quarterly Journal of Economics, 120(1): 45-86.

Goette, Lorenz, David Huffman, and Stephan Meier. 2006. "The Impact of Group Membership on Cooperation and Norm Enforcement: Evidence using Random Assignment to Real Social Groups.” American Economic Review 96(2): 212-216.

Goldstein, Joshua S. 2003. War and Gender: How Gender Shapes the War System and Vice Versa. Cambridge, MA: Cambridge University Press.

Greiner, Ben. 2004. "The Online Recruitment System ORSEE 2.0 - A Guide for the Organization of Experiments in Economics." University of Cologne Working Papers Series in Economics, 10.

Greiner, Ben and Vittoria M. Levatti. 2005. "Indirect Reciprocity in Cyclical Networks. An Experimental Study.” Journal of Economic Psychology 26: 711-731.

Guala, Francesco. 2012. "Reciprocity: Weak or Strong? What Punishment Experiments Do (and Do Not) Demonstrate." Behavioral and Brain Sciences, 35(1): 1.

Güth, Werner, Rolf Schmittberger, and Bernd Schwarze. 1982. “An experimental analysis of ultimatum bargaining.” Journal of Economic Behavior and Organization 3(4): 367-388.

Habyarimana, James P., Macartan Humphreys, Daniel N. Posner, and Jeremy M. Weinstein. 2009. Coethnicity: Diversity and the Dilemmas of Collective Action, New York: Russell Sage Foundation Publications.

Hardin, Russel. 1995. One For All: The Logic of Group Conflict. Princeton, NJ: Princeton University Press.

Hargreaves-Heap, Shaun, and Daniel J. Zizzo. 2009. “The Value of Groups.” American Economic Review, 99(1): 295-323.

Hoff, Karla, Mayuresh Kshetramade, and Ernst Fehr. 2011. "Caste and Punishment: The Legacy of Caste Culture in Norm Enforcement." The Economic Journal 121 (556): F449-F475. 
Honaker, James, Gary King, and Matthew Blackwell. 2012. "Amelia II: A Program for Missing Data." $R$ package.

Horowitz, Donald N. 1985. Ethnic Groups in Conflict. Berkeley: University of California Press.

Horowitz, Donald N. 2001. The Deadly Ethnic Riot. Berkeley: University of California Press.

Kaufman, Stuart J. 2001. Modern Hatreds: The Symbolic Politics of Ethnic War. Ithaca, NY:

Cornell University Press.

Keynes, John M. 1922. The Economic Consequences of the Peace. Los Angeles, CA: IndoEuropean.

Klein, Jill Gabrielle, and Richard Ettensoe. 1999. "Consumer Animosity and Consumer Ethnocentrism.” Journal of International Consumer Marketing 11 (4): 5-24.

Leong, Siew Meng, Joseph A. Cote, Swee Hoon Ang, Soo Jiuan Tan, Kwon Jung, Ah Keng Kau, and Chanthika Pornpitakpan. 2008. "Understanding Consumer Animosity in an International Crisis: Nature, Antecedents, and Consequences." Journal of International Business Studies 39(6): 996-1009.

Lickel, Brian, Norman Miller, Douglas M. Stenstrom, Thomas F. Denson, and Toni Schmader. 2006. "Vicarious Retribution: The Role of Collective Blame in Intergroup Aggression.” Personality and Social Psychology Review, 10(2): 372-703.

Mummendey, Amélie, Bernd Simon, Carsten Dietze, Melanie Grünert, Gabi Haeger, Sabine Kessler, Stephan Letgen, and Stefanie Schäferhoff. 1992. "Categorization is Not Enough: Intergroup Discrimination in Negative Outcome Allocations." Journal of Experimental Social Psychology, 28: 125-144.

Rabin, M. 1993. "Incorporating fairness into game theory and economics." American Economic Review, 83(5):1 281-1302.

Shayo, M., and A. Zussman. 2011. "Judicial Ingroup Bias in the Shadow of Terrorism." The Quarterly Journal of Economics 126 (3): 1447-1484.

Sherif, Muzafer, O. J. Harvey, B. Jack White, William R. Hood, and Carolyn W. Sherif. 1961. The Robbers Cave Experiment: Intergroup Conflict and Cooperation. Scranton, PA: Wesleyan University Press.

Sen, Amartya. 2007. Identity and Violence: The Illusion of Destiny. W. W. Norton \& Company. Stenstrom, Douglas M., Brian Lickel, Thomas F. Denson, and Norman Miller. 2008. The Roles of Ingroup Identification and Outgroup Entitativity in Intergroup Retribution. Personality and Social Psychology Bulletin, 34: 1570-1582.

Tajfel, Henri, M. G. Billig, R. P. Bundy, and Claude Flament. 1971. "Social Categorization 
and Intergroup Behavior.” European Journal of Social Psychology, 1(2): 149-178.

Tambiah, Stanley J. 1996. Leveling Crowds: Ethnonationalist Conflicts and Collective Violence in South Asia. Berkeley: University of California Press.

Weisel, Ori and Ro'i Zultan. 2013. "Social Motives in Intergroup Conflict.” Jena Economic Research Papers 2013-033.

World Bank. 2011. The World Development Report 2011:Conflict, Security, and Development. Washington D.C.: The World Bank.

Zussman, Asaf. 2012. "Ethnic Discrimination: Lessons from the Israeli Online Market For Used Cars.” Working paper. 